\title{
FOREST COVER CHANGE ANALYSIS IN INNER MONGOLIA USING REMOTE SENSING DATA
}

\author{
S. Xie, J. Gong, X Huang
}

School of Remote Sensing and Information Engineering, Wuhan University, Wuhan 430079, China-simeixie@126.com

KEY WORDS : Forest cover change, Remote sensing data, Inner Mongolia, Land use and land cover data

\begin{abstract}
ABS TRACT:
Forest is the lung of the earth, and it has important effect on maintaining the ecological balance of the whole earth. This study was conducted in Inner Mongolia during the year 1990-2015. Land use and land cover data were used to obtain forest cover change of Inner Mongolia. In addition, protected area data, road data, ASTER GDEM data were combined with forest cover change data to analy ze the relationship between them. Moreover, patch density and landscape shape index were calculated to analyze forest chan ge in perspective of landscape aspect. The results indicated that forest area increased overall during the study period. However, a few cities still had a phenomenon of reduced forest area. Results also demonstrated that the construction of protected area had positive effect on protecting forest while roads may disturbed forest due to human activities. In addition, forest patches in most of cities of Inner Mongolia tended to be larger and less fragmented. This paper reflected forest change in Inner Mongolia objectively, which is helpful for policy making by government.
\end{abstract}

\section{INTRODUCTION}

Forest plays a vital role in maintaining the ecological balance of the earth. Forests can not only regulate the circulation of air and water, influence climate change, but also conserve water and prevent wind and sand ( $\mathrm{Hu} \mathrm{X}$ et al., 2014). However, with the development of urbanization, deforestation, construction of towns, logging of timber, fire and insect pests have reduced the forest area. Loss of forest can cause soil erosion, loss of biodiversity, climate change and other ecological problems. In order to protect forest resources, China has implemented a number of policies and measures, such as the National Forest Protection Program (NFPP), Grain-to-Green Project and Green Ecological Protection Belts Program (GEPBP) (Wu J et al., 2015; Wang Z et al., 2017). NFPP was implemented in 2000, and it is in its second period (2011-2020) now (Shi M et al., 2017). Besides banning commercial logging, the goal of this program was also to improve forest management as well as to promote the local economy (NFPP Management Center, 2011). Grain-toGreen Project aimed to stop planting on the slope farmland and planting trees in accordance with local conditions. It included two aspects: one was planting trees on slope farmland instead of farming, the other was afforesting on arable hills and wasteland. Due to the deforestation, northern cities suffered from sand storm, thus GEPBP was launched to solve these problems.

Inner Mongolia, one of the provinces with rich forest resources in China, has original forests, secondary forests and artificial forests from the east to the west. At the same time, Inner Mongolia is also one of the provinces with the most concentrated desertification, the most serious and most vulnerable ecological environment. Therefore, it is necessary to monitor and analyze the forest change in Inner Mongolia. Many studies have focused on forest biomass (Zhang M et al., 2017), carbon storage (Zhang Y et al., 2010) and the influence of fire (Jia X et al., 2017). The objective of our research is to detect and analyze the forest change in Inner Mongolia from 1990 to 2015 and to find out the drivers of forest change.

\section{DATA AND METHOD}

The study area, Inner Mongolia, is located in the northern border of China (Figure 1). It runs more than 28 degree of longitude from west to east, covering an area of 1183000 square kilometers. Its elevation descends from west to east, with an average elevation of about 1000 meters above the sea level. Most of the forest resources are concentrated in the northern mountains of Daxing'an Mountains.

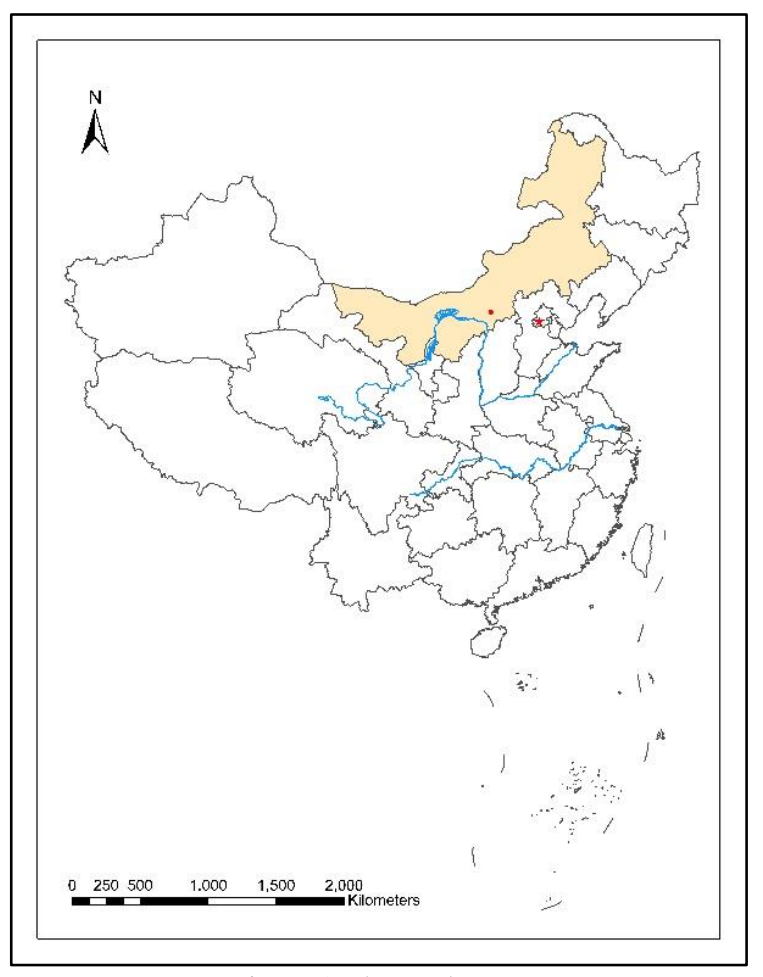

Figure 1.The study area 
The main datasets used in this research were land use and land cover data (LUCD) in 1990, 1995, 2000, 2005, 2010 and 2015 with $30 \mathrm{~m}$ spatial resolution. The datasets were provided by Data Center for Resources and Environmental Sciences, Chinese Academy of Sciences (RESDC) (http://www.resdc.cn). The production of this data was based on the Landsat TM/ETM remote sensing image as the main data source, which was generated by artificial visual interpretation. The types of land use include arable land, woodland, grassland, water area, residential area and unused land. Woodland comprises thick forest, shrubbery, open forestland and other woodland. In this study, woodland with a canopy density of more than $10 \%$ is defined as forest (Joseph O. Sexton et al., 2016), which contains the first three types of woodland. In addition, a shapefile of protected areas (PAs) was obtained from the World Database on Protected Areas (WDPA). The World Database on Protected Areas (WDPA) is the largest assembly of data on the world's terrestrial and marine protected areas, containing more than 200,000 protected areas as of October 2017, with records covering 245 countries and territories throughout the world (UNEP-WCMC, 2017). Data for the WDPA was collected from international convention secretariats, governments and collaborating nongovernment organizations. There were 33 protected areas in Inner Mongolia, and most of them were set up in the 1980s. To analyze the relationship between forest change and the distance to roads, a shapefile of main roads was used in this study. Meanwhile, ASTER GDEM data of Inner Mongolia were provided by Geospatial Data Cloud site, Computer Network Information Center, Chinese Academy of Sciences. (http://www.gscloud.cn).

In this study, the changes of forest area were obtained by means of overlay analysis, then the relationship between forest change and PAs or roads were received through buffer analy sis and forest landscape changes were evaluated by calculating patch density and landscape shape index. Firstly, the LUCD of adjacent years were analyzed at provincial level as well as prefectural level to obtain forest changes in ArcGIS10.1, including forest loss, forest gain, the whereabouts of forest loss and the source of forest gain. Secondly, buffers of both the shapefile of main roads and PAs were established, which were used to analyze the factors affecting forest change by combining with forest changes mentioned above. Buffer zones were built at every kilometer on the whole road layer (Hu X et al., 2016). And the buffer zones of PAs were $0-5 \mathrm{~km}, 5-10 \mathrm{~km}, 10-15 \mathrm{~km}$ and $15-20 \mathrm{~km}$ respectively (Liu F et al., 2016). Thirdly, slope data were produced by DEM to evaluate the effect of elevation. Slope was classified into 7 categories: 1. flat slope (0-5 degree), 2. gentle slope (6-15 degree), 3. ramp (16-25 degree), 4. steep slope (26-35 degree), 5. very steep slope (36-40 degree), 6. abrupt slope (41-45 degree), 7. dangerous slope ( $>45$ degree). Finally, landscape metrics were calculated in the Fragstats. Patch density equals the number of patches of the corresponding patch type divided by total landscape area, multiple by 10000 and 100 . It can reflect the degree of differentiation of the overall landscape plaque. Landscape shape index equals 0.25 times the sum of the entire landscape boundary and all edge segments within the landscape boundary, including some or all of those bordering background, divided by the square root of the total landscape area, which can indicate the complexity of the shape of the patch. The closer the landscape shape index is to 1 , the closer the shape of the patch to a square of a circle.

\section{RESULTS AND ANALYS IS}

Overall, forest areas of Inner Mongolia increased from 162298.6 $\mathrm{km}^{2}$ in 1990 to $173266.51 \mathrm{~km}^{2}$ in 2015 with the largest area of $176339.47 \mathrm{~km}^{2}$ in 2010 (Figure 2). After a gradual increase from 1990 to 2000, a slight drop appeared, then a sharp rise was witnessed from 2005 to 2010 followed by an obvious fall at the end. The year 2000 was a key point for the transformation of the forest in Inner Mongolia, where forest loss was more than forest gain, then the forest showed a net growth in 2000-2010. In the 21 st century, the forestry ecological construction in Inner Mongolia entered a stage of rapid development because of the protection measures made by the Chinese government. In the early 21 st century, in order to combat dust storms and improve the environment of Beijing, government initiated a series of projects, including the Beijing-Tianjin Wind and Sand Source Control Project, the Natural Forest Protection Project, and etc.

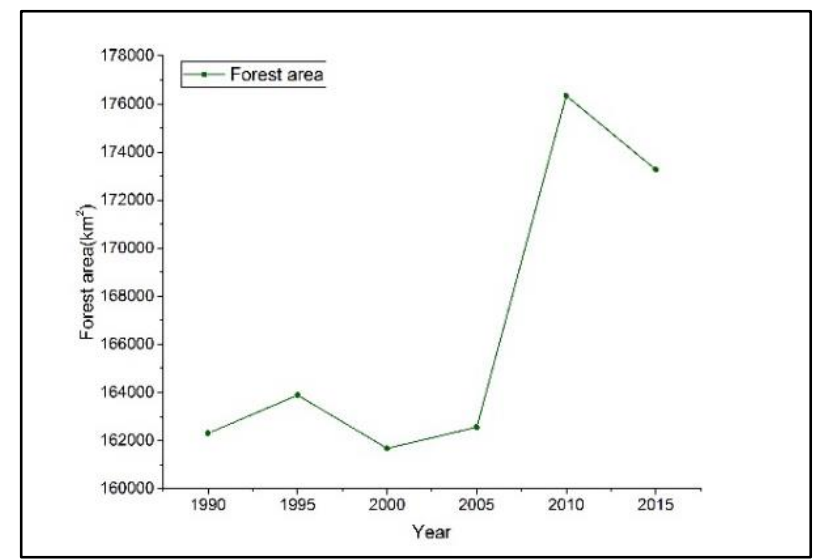

Figure 2. Forest cover change in Inner Mongolia

Among all the forest loss, over $40 \%$ percent were converted to grassland, the others were mainly converted to unused land and arable land (Figure 3). In the meantime, a majority of the forest gain were came from grassland. The transformation between forest and grassland occurred frequently. Notably, over half of the forest loss were transformed to arable land from 1995 to 2000. The Grain-to-green project was implemented in 2002, therefore, the area of forest to arable land reduced in the following years. In addition, $37 \%$ percent of the forest loss that located in the southeastern Inner Mongolia turned into other woodland, which contains immature forestland, slash, nursery and other orchard land from 2000 to 2005.

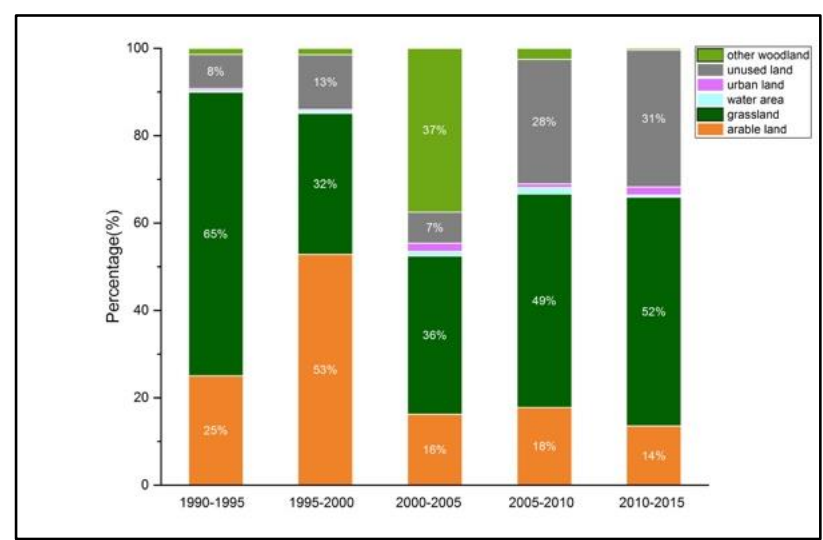

Figure 3. The whereabouts of forest loss

From the perspective of municipal level, forest area of most city raised except Alashan and Hulunbuir (Figure 4). Forest area in Hulunbuir was the largest while Wuhai had the least forest area. In 1990-2005, the forest area of each city tended to be stable, and 
the forest area of most cities increased in 2005-2010, especially in Chifeng and Tongliao, while the forest area of most cities decreased from 2010 to 2015. Most of the cities with more forest loss are located in the eastern part of Inner Mongolia, in which had the largest forest area. During 1995 to 2000, the percentage of the forest loss to arable land and grassland was $72 \%$ and $27 \%$ respectively, then the former decreased while the latter increased in the following years in Chifeng. In the last five years, up to $91 \%$ of the forest loss were converted into grassland as just $6 \%$ were transformed to arable land. Aohan Banner, which is located in the southeastern Chifeng, was a major agriculture county that most of the forestland was converted into arable land. From 1990 to 2005, the forest loss were mainly converted into arable land in Tongliao while most of the forest loss became grassland from 2005 to 2015. During 1990 to 1995 and 2005 to 2010, the area of forest gain was much larger than that of forest loss as the area of forest loss was larger in 2010-2015 in Tongliao. During the year 2010 to 2015 , up to $85 \%$ of the forest loss were transformed to grassland, which happened mainly in the northeastern Horqin grassland. As for Hulunbuir, with the most forest area, forest loss happened mainly in the east. Forest in Hinggan were mostly converted to grassland and arable land, which occurred in the east of Zhanlaite. Moreover, forest area in Xilinguole fluctuated frequently. Forest were mainly transformed to grassland and the largest source of forest gain was also grassland.

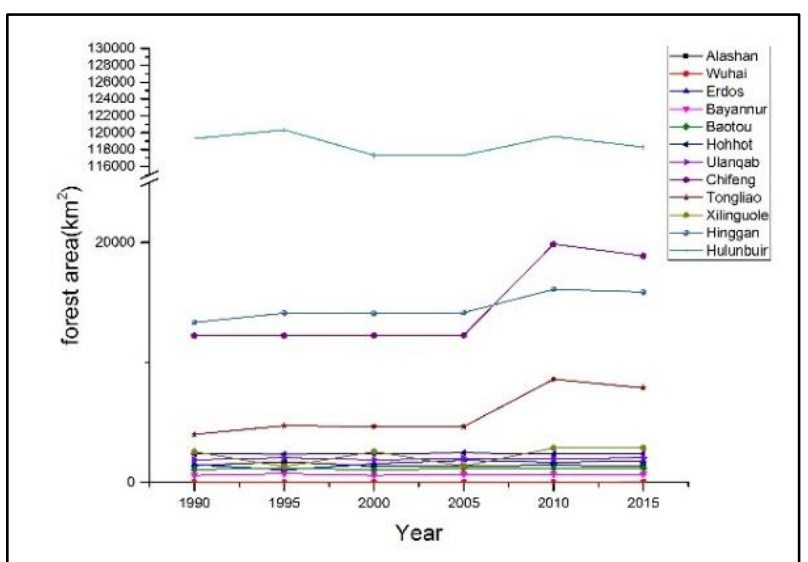

Figure 4. Forest cover change of different cities in Inner Mongolia

The establishment of PAs was helpful for improving environment, keeping the balance of nature and achieving sustainable development. According to WDPA, there were 33 PAs in Inner Mongolia, and the total area of PAs were $3840 \mathrm{~km}^{2}$. As expected, the results showed that the farther from PAs, the more loss of forest (Figure 5). The tendency of forest gain was the same as that of forest loss in the buffers of PAs. The results illustrated that the establishment of PAs was of positive significance to the forest protection. Between 1990 and 2000, the hugest losses of forest occurred in the protected area of forest for conservation of water supply in Helan mountain. During the year 2000 to 2010, Xilin Gol Steppe Protected area and Honghuaerji pinus forest protected area gained more forest. Moreover, Hanma National Nature Reserve lost most forest, while east Erdos National Nature Reserve gained most forest. As for the effect of roads, results also indicated that distance from road is inversely proportional to the ratio of forest loss. While, as the distance from road increased, ratio of forest raised. An interesting finding was that the ratio of forest gain increased with the decrease of the distance from road.

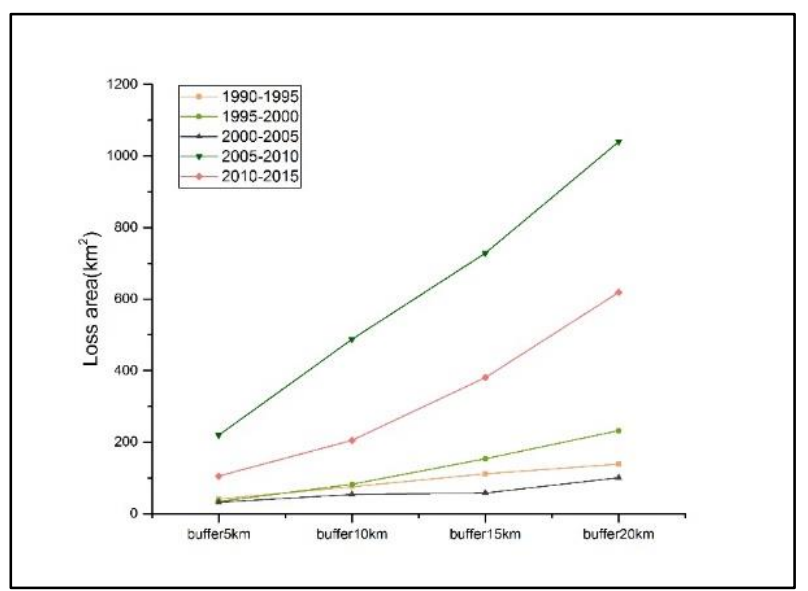

Figure 5. Forest loss in different buffers

Inner Mongolia had about 37\%, $42 \%$ and $11 \%$ of flat slope, gentle slope and ramp, respectively, where most of the forest distributed. More than half of the forest were on the gentle slope. In particulate, steeper land had larger forest growth rate that the forest growth rate of dangerous slope was the largest rate among all categories of slope with over 20\%. Additionally, the proportion of forest on the land with slope of over 5 degree increased between 1990 and 2015. As mentioned in the policy of Grain-to-Green Project, open forestland, arable hills and wasteland were the primary reforestation objectives.

As for the landscape metrics, patch density (PD) and landscape shape index (LSI) were calculated on class level. PD of most cities presented a steady state except for Hinggan, Hohhot and Chifeng (Figure 6). PD of all of these three cities fluctuated wildly. PD of Hinggan and Chifeng had a sharply drop from 2005 to 2010. In 2005, forests were fragmentized, then they connected together in 2010, which meant that the patches decreased and the fragmentation also had a decline. Forest area of Chifeng increased in 2010, however, the number of patches decreased, thus, its patch density dropped. PD of Hohhot descended firstly and then rose again between 1990 and 2000. Though forest area of Hohhot changed only dozens of kilometers, patches in 1995 was less than those in 1990, whereas patches in 2000 was more than those in 1995.

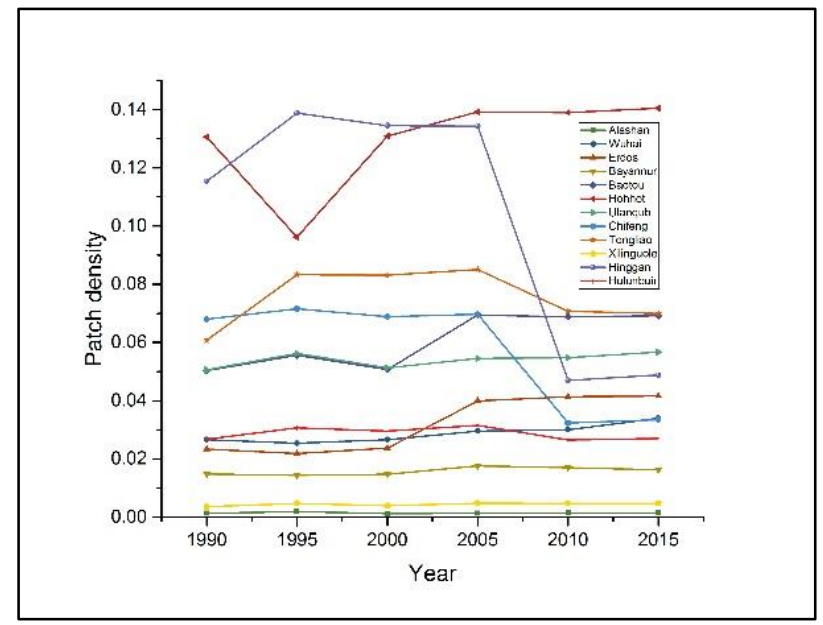

Figure 6. Patch density of cities in Inner Mongolia

Otherwise, LSI of Hinggan, Tongliao and Chifeng declined in 2010 (Figure 7), which meant that forest patches became regular, while LSI of Erdos grew from 2000 to 2010, which demonstrated 
that human disturbance had caused forest patches became irregular during this period in Erdos.

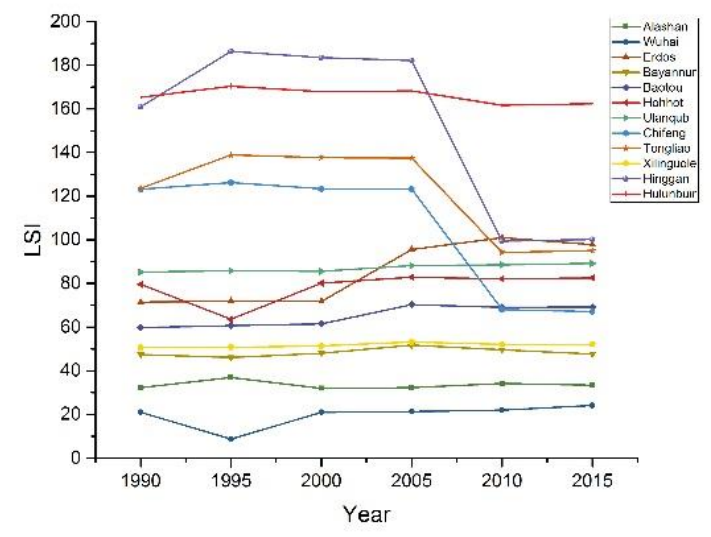

Figure 7. Landscape shape index of cities in Inner Mongolia

\section{CONCLUSIONS}

In this study, forest cover change in Inner Mongolia were statically analyzed from 1990 to 2015 , which revealed that forest area in Inner Mongolia increased $0.44 \%$ annually. It also concluded that the conversion between forest and grassland occurred most frequently. PAs have positive effect on forest protection. Moreover, the distance from road is inversely proportional to forest change. Slope is another important factor that caused forest change. The results of landscape metrics analy sis illustrated that forest patches increased and the shape of forest patches became more regular. In summary, this study is useful for PAs construction as well as forest protection management.

\section{REFERENCES}

Hu X, Wu C, Hong W, Qiu R, Li J, Hong T. (2014). Forest cover change and its drivers in the upstream area of the Minjiang River, China. Ecological Indicators, 46(11), pp. 121-128.

Liu F, Huang C, Pang Y, Li M, Song D, Song X, Saurabh Channan, Joseph O. Sexton, Jiang D, Zhang P, Guo Y, Li Y, John R. Townshend. (2016). Assessment of the three factors affecting Myanmar's forest cover change using Landsat and MODIS vegetation continuous fields data. Digital Earth, 9(6), pp. 562585 .

Joseph O., Praveen N., Song X, Feng M, Song D, Kim D, Anupam Anand, Huang C, Saurabh Channan, Stuart L. Pimm, John R. Townshend. (2016). Conversion policy and the measurement of forests. Nature Climate Change, 6, pp. 192-197.

NFPP M anagement Center. (2011). Authoritative Interpretations for the Second Phase Policies of Natural Forest Protection Project (In Chinese).

Shi M, Yin R, Lv H. (2017). An empirical analy sis of the driving forces of forest cover change in northeast China. Forest Policy and Economics, 78(2017), pp.78-87.
UNEP-WCMC (2017). Protected areas map of the world, October 2017. Available at: www.protectedplanet.net.

Wang Z, Deng X, Song W, Li Z, Chen J. (2017). What is the main cause of grassland degradation? A case study of grassland ecosystem service in the middle-south Inner Mongolia. Catena, 150(2017), pp. 100-107.

Wu J, Zhang Q, Li A, Liang C. (2015). Historical landscape dynamics of Inner Mongolia: patterns, drivers, and impacts. Landscape Ecology, 30(9), pp. 1579-1598.

Jia X, Gao Y, Wei B, Yang G, Dang X, Ren Y, Liang C. (2017). Impact of topographic features on the distribution of fire based on MODIS data in Inner Mongolia, northern China. Journal of Beijing Forestry University, 39(5), pp.34-40.

Zhang M, Wang G, Gao Y, Wang Z, Mi F. (2017). Trade-Offs between Economic and Environmental Optimization of the Forest Biomass Generation Supply Chain in Inner Mongolia, China. Sustainability, 9(11), pp. 2030.

Zhang Y, Liu H. (2010). How did climate drying reduce ecosystem carbon storage in the forest steppe ecotone? A case study in Inner Mongolia. Journal of Plant Research, 123(4), pp. 543-549. 